\title{
Combined inhibition of morphogen pathways demonstrates additive antifibrotic effects and improved tolerability
}

\author{
Alfiya Distler, ${ }^{1}$ Veronika Lang, ${ }^{1}$ Tina Del Vecchio, ${ }^{1}$ Jingang Huang, ${ }^{1}$ Yun Zhang, ${ }^{1}$ \\ Christian Beyer, ${ }^{1}$ Neng-Yu Lin, ${ }^{1}$ Katrin Palumbo-Zerr, ${ }^{1}$ Oliver Distler, ${ }^{2}$ Georg Schett, ${ }^{1}$ \\ Jörg HW Distler ${ }^{1}$
}

Handling editor Tore K Kvien

- Additional material is published online only. To view please visit the journal online (http://dx.doi.org/10.1136/ annrheumdis-2013-204221)

1 Department of Internal Medicine 3 and Institute for Clinical Immunology, University of Erlangen-Nuremberg, Germany

2Department of Rheumatology, University Hospital Zurich, Zurich, Switzerland

Correspondence to Dr Jörg HW Distler,

Department of Medicine 3 and Institute for Clinical Immunology, University of Erlangen-Nuremberg, Ulmenweg 18, Erlangen D-91054, Germany; Joerg.distler@uk-erlangen.de

$A D, V L$ and TDV contributed equally.

Received 3 July 2013

Revised 27 December 2013

Accepted 2 January 2014

Published Online First

20 January 2014

\section{ABSTRACT}

Objectives The morphogen pathways Hedgehog, Wnt and Notch are attractive targets for antifibrotic therapies in systemic sclerosis. Interference with stem cell regeneration, however, may complicate the use of morphogen pathway inhibitors. We therefore tested the hypothesis that combination therapies with low doses of Hedgehog, Wnt and Notch inhibitors maybe safe and effective for the treatment of fibrosis.

Methods Skin fibrosis was induced by bleomycin and by overexpression of a constitutively active TGF- $\beta$ receptor type I. Adverse events were assessed by clinical monitoring, pathological evaluation and quantification of Lgr5-positive intestinal stem cells.

Results Inhibition of Hedgehog, Wnt and Notch signalling dose-dependently ameliorated bleomycininduced and active TGF- $\beta$ receptor type I-induced fibrosis. Combination therapies with low doses of Hedgehog/Wnt inhibitors or Hedgehog/Notch inhibitors demonstrated additive antifibrotic effects in preventive as well as in therapeutic regimes. Combination therapies were well tolerated. In contrast with high dose monotherapies, combination therapies did not reduce the number of Lgr5 positive intestinal stem cells. Conclusions Combined inhibition of morphogen pathways exerts additive antifibrotic effects. Combination therapies are well tolerated and, in contrast to high dose monotherapies, may not impair stem cell renewal. Combined targeting of morphogen pathways may thus help to overcome dose-limiting toxicity of Hedgehog, Wnt and Notch signalling.

\section{INTRODUCTION}

The complex pathogenesis of many rheumatological diseases, including rheumatoid arthritis and pulmonary arterial hypertension, ${ }^{1}{ }^{2}$ is stimulating the development of combination therapies that modulate different pathways involved in the disease process. Combinations therapies offer several advantages over monotherapies. Simultaneous inhibition of several disease pathways may have additive effects and increase efficacy. This in turn may allow decreasing the doses of single compounds of the combination regimen, which results in better tolerability with decreased frequency and intensity of drug related toxicities. So far, however, combination therapies have not yet been evaluated for the treatment of fibrotic diseases.
Morphogen pathways such as Hedgehog, Wnt and Notch signalling have recently been characterised as master regulators of fibroblast activation in systemic sclerosis (SSc) and other fibrotic diseases. $^{3-14}$ Inhibition of either Hedgehog, Wnt or Notch signalling has potent antifibrotic effects in various preclinical models of SSc. ${ }^{3-5} 7-911121516$ These findings may have direct translational implications because several potent and selective inhibitors of these pathways are in clinical trials or already approved. Hedgehog, Wnt and Notch signalling pathways, however, also regulate proliferation and differentiation of stem cells. Long-standing inhibition of these pathways as required in chronic diseases, such as SSc, may cause depletion of stem cells and impair tissue regeneration. ${ }^{17} 18$ Resulting toxicities, in particular in tissues and organs with high cell turnover, such as the intestine, may limit the use of higher doses of morphogen pathway inhibitors in humans. Lower doses of Hedgehog, Wnt and Notch inhibitors with only partial inhibition of the morphogen pathways may warrant regenerative capacity of stem cells, but may not be as effective for the treatment of fibrosis.

Here, we tested the hypothesis that combination therapies with low doses of inhibitors of different morphogen pathways may overcome stem cell toxicity and have additive antifibrotic effects and better tolerability than high dose monotherapies.

\section{MATERIALS AND METHODS \\ Inhibition of morphogen pathways in experimental fibrosis}

Skin fibrosis was induced in DBA/2 mice (Janvier, Le Genest Saint Isle, France) by subcutaneous injections of bleomycin or in $\mathrm{C} 57 \mathrm{Bl} / 6$ mice by overexpression of active TGF- $\beta$ receptor type I (AdTBR) as described. ${ }^{3} 1619$ Hedgehog signalling was targeted with cyclopamine $(5 \mathrm{mg} / \mathrm{kg} / \mathrm{d}$ and $15 \mathrm{mg} / \mathrm{kg} / \mathrm{d}$ intraperitoneally, LC Labs, Woburn, Massachusetts, USA). Canonical Wnt and Notch signalling were inhibited as described with ICG-001 (2 mg/kg/d and $4 \mathrm{mg} / \mathrm{kg} / \mathrm{d}$, Enzo Life Sciences, Loerrach, Germany) and DAPT ( $\gamma$-secretase inhibitor) (1.5 $\mathrm{mg} / \mathrm{kg} / \mathrm{d}$ and $6 \mathrm{mg} / \mathrm{kg} / \mathrm{d}$, Sigma-Aldrich, Steinheim, Germany), respectively. In the mouse model of bleomycin-induced fibrosis, treatment was initiated upon first injection of bleomycin. In contrast, in 
AdTBR model, treatment was initiated 4 weeks after AdTBR injection, when fibrosis was already established.

The antifibrotic effects were analysed by quantification of skin thickness, hydroxyproline content and $\alpha$-smooth muscle actin counts as described. ${ }^{3-5} 7919$ Five to seven samples per group were analysed.

\section{Evaluation of the safety profile}

Mice were monitored daily for body weight, food intake, texture of the fur, activity and quality of the stool according to established protocols. ${ }^{8} 15$ The effect of treatment on intestinal stem cells was analysed by staining for Lgr5-positive cells using rabbit polyclonal antibody (Abcam, Cambridge, UK). Lgr5-positive intestinal stem cells were counted in at least four different areas at 400-fold magnification in a blinded manner.

\section{Statistics}

All data are presented as median with IQR, and differences between the groups were tested for their statistical significance by non-parametric Mann-Whitney U test.

\section{RESULTS}

\section{Combined inhibition of morphogen pathways exerts additive antifibrotic effects}

Inhibition of single morphogen pathways by preventive treatment with cyclopamine, ICG-001 or DAPT potently reduced bleomycin-induced fibrosis in a dose-dependent manner with significant decreases in dermal thickening, numbers of myofibroblasts and hydroxyproline content, even at low doses (figure $1 \mathrm{~A}-\mathrm{C})$. Simultaneous targeting of morphogen pathways by combination therapies showed additive antifibrotic effects. The decreases in dermal thickening, myofibroblast counts and the hydroxyproline content were significantly more pronounced upon combination therapy cyclopamine/ICG-001 or cyclopamine/DAPT than with single therapy in comparable doses (figure 1A-C). The antifibrotic effects of preventive treatment with low doses of morphogen pathway inhibitors given in combination were comparable with that of high doses of individual inhibitors.

\section{Combination therapies of low doses of morphogen pathway inhibitors prevents depletion of intestinal stem cells}

Depletion of stem cells with subsequent toxicity to organs with a high cell turnover, such as the intestine, has been a major concern when targeting morphogen pathways. ${ }^{18}$ We hypothesised that combination therapy with low doses of inhibitors of different morphogen pathways may allow for sufficient proliferation and differentiation of stem cells. Indeed, we did not observe clinical evidence of gastrointestinal toxicity such as diarrhoea or weight loss in mice treated with low dose monotherapies or with cyclopamine/ICG-001 or cyclopamine/DAPT. In contrast, the recovery from bleomycin-induced weight loss was delayed with high dose monotherapies (see online supplementary figure S1). Texture of the fur and activity of the treated mice also did not differ from control animals. Macroscopic and microscopic evaluation of the ileum and the jejunum of mice receiving low-dose combination therapies did not show any differences compared with sham-treated mice. Moreover, staining for Lgr5, which has been characterised as a highly selective pan-intestinal stem cell marker, ${ }^{20}$ demonstrated low doses of morphogen pathway inhibitors, in either mono therapies or combination therapies, do not decrease the number of pluripotent stem cells in the gut (figure 2A, B). By contrast, high doses of either Hedgehog, Wnt or Notch inhibitors significantly reduced the number of Lgr5 positive stem cells.

\section{Combined inhibition of morphogen pathways is effective in pre-established AdTBR-induced skin fibrosis}

To analyse the antifibrotic effects of combined inhibition of morphogen pathways in non-inflammatory model of fibrosis, we employed the mouse model of AdTBR-induced skin fibrosis. In contrast with the preventive approach in bleomycin-induced fibrosis, treatment in the AdTBR model was initiated only after fibrosis had already been manifested. Inhibition of canonical Wnt signalling was more effective in established AdTBR-induced skin fibrosis than inhibition of Notch and Hedgehog signalling with more pronounced effects of ICG-001 as compared with DAPT and cyclopamine at both doses. Moreover, the combination of Wnt and Hedgehog inhibition is more effective than combined inhibition of Notch and Hedgehog signalling. Combination therapies with Notch and Hedgehog inhibitors and intraperitoneally with Wnt and Hedgehog inhibitors were more effective than monotherapies. Treatment with cyclopamine/ICG-001 did prevent progression of fibrosis, and induced regression of preestablished fibrosis with decreases in dermal thickness, in myofibroblast counts and in hydroxyproline content to below pretreatment levels (figure $3 \mathrm{~A}-\mathrm{C}$ ).

\section{DISCUSSION}

Hedgehog, Wnt or Notch signalling are key players in fibrosis. Since several inhibitors for each of these morphogen pathways are in clinical trials or already approved, Hedgehog, Wnt and Notch signalling are attractive candidates for targeted therapies of fibrotic diseases. 379111318 Morphogen pathways also maintain stem cell activity and tissue regeneration, however, toxicities to tissues and organs with a high turnover have always been a concern when considering clinical applications. ${ }^{17} 18$ Indeed, we show here that chronic treatment with high doses of either Hedgehog, Wnt or Notch inhibitors induce depletion of Lgr5-positive intestinal stem cells. In contrast, low doses of morphogen inhibitors with only partial inhibition of the respective pathway did not decrease the number of pluripotent intestinal stem cells and was not limited by other adverse events. The tolerability of combination therapies may be explained by the distinct functions of morphogen pathways in stem cell maintenance and their activation at different compartments. Wnt and Notch pathways stimulate predominantly proliferation of stem cells at the bottom of the crypt, whereas Hedgehog signalling regulates differentiation of stem cells as they migrate upwards the crypts. ${ }^{17}$

We also demonstrate for the first time that combined inhibition of morphogen pathways exerts additive antifibrotic effects in two mouse models of skin fibrosis, one resembling inflammatory subsets of patients and the other one mimicking noninflammatory stages. The additive antifibrotic effects were observed in preventive as well as in therapeutic settings. Simultaneous inhibition of Hedgehog/Wnt or Hedgehog/Notch signalling decreased dermal thickening, collagen accumulation and myofibroblast differentiation more effectively than monotherapies. Combination therapies with low doses of morphogen inhibitors were as potent as monotherapies with high doses.

Together, our data suggest that combinations of morphogen inhibitors are effective in murine models of SSc, and that their use may, in contrast with high dose monotherapies, not be limited by stem cell depletion. Although these data are encouraging, additional studies are needed to further characterise the efficacy and tolerability of combination therapies. (1) Despite absence of clinical tolerability, healthy microscopic architecture 

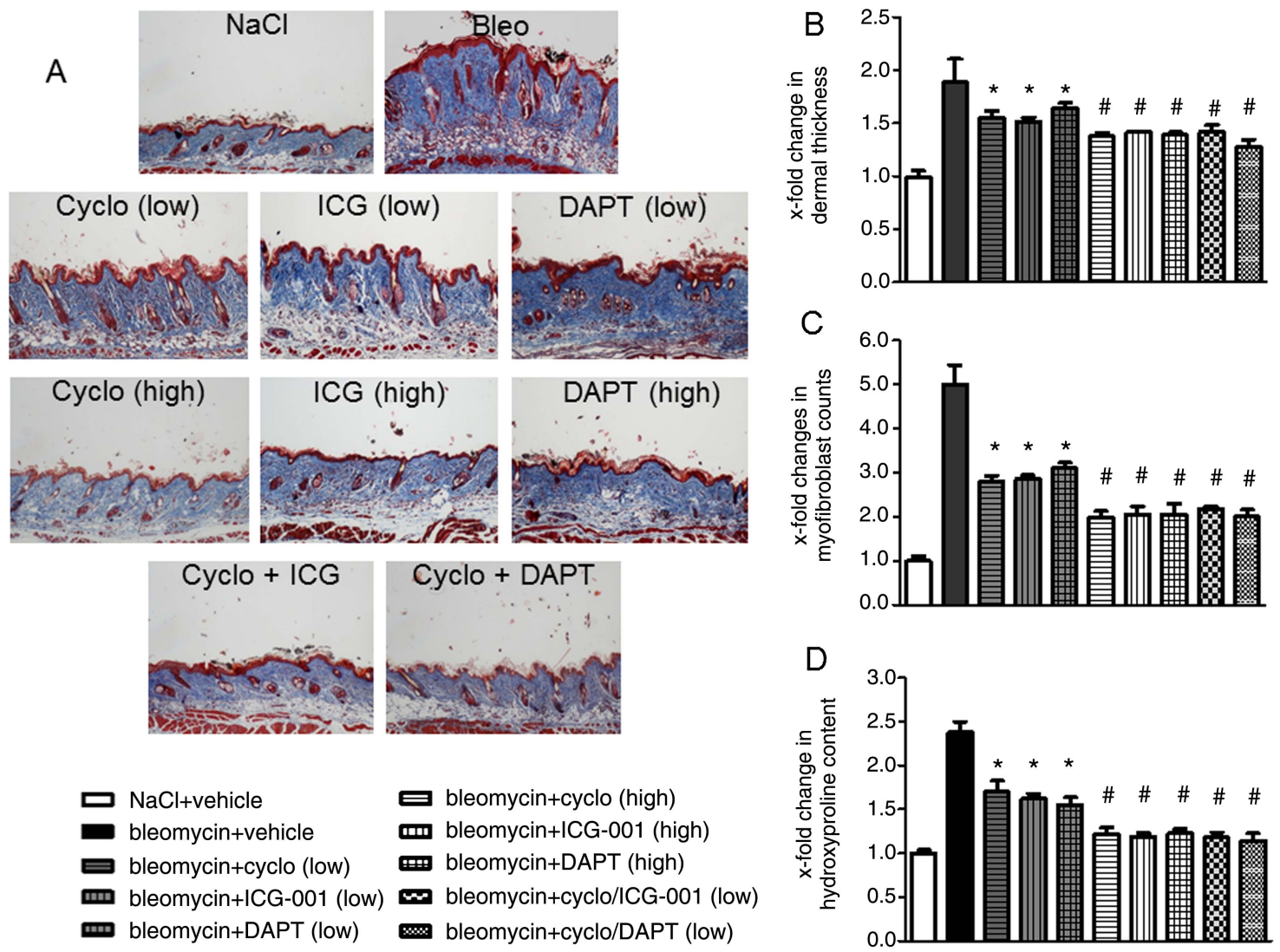

Figure 1 Combined inhibition of morphogen pathways exerts additive antifibrotic effects. (A) Representative Trichrome stained skin section of mice receiving single and combination therapies at 100-fold magnification. Effects of the different treatment regimens on skin thickening (B), myofibroblast differentiation (C) and hydroxyproline content (D). * indicates significant differences compared with vehicle-treated, bleomycin-challenged mice. \# indicates significant decreases compared with low-dose monotherapy.

of the gut and normal numbers of Lgr5 positive stem cells, we cannot exclude that combined inhibition of morphogen pathways may affect particular subsets of stem cells in the intestine or in other organs. (2) The effect of combination therapies on other manifestations of SSc such as vascular diseases demands particular attention. (3) The interaction of Hedgehog, Wnt or
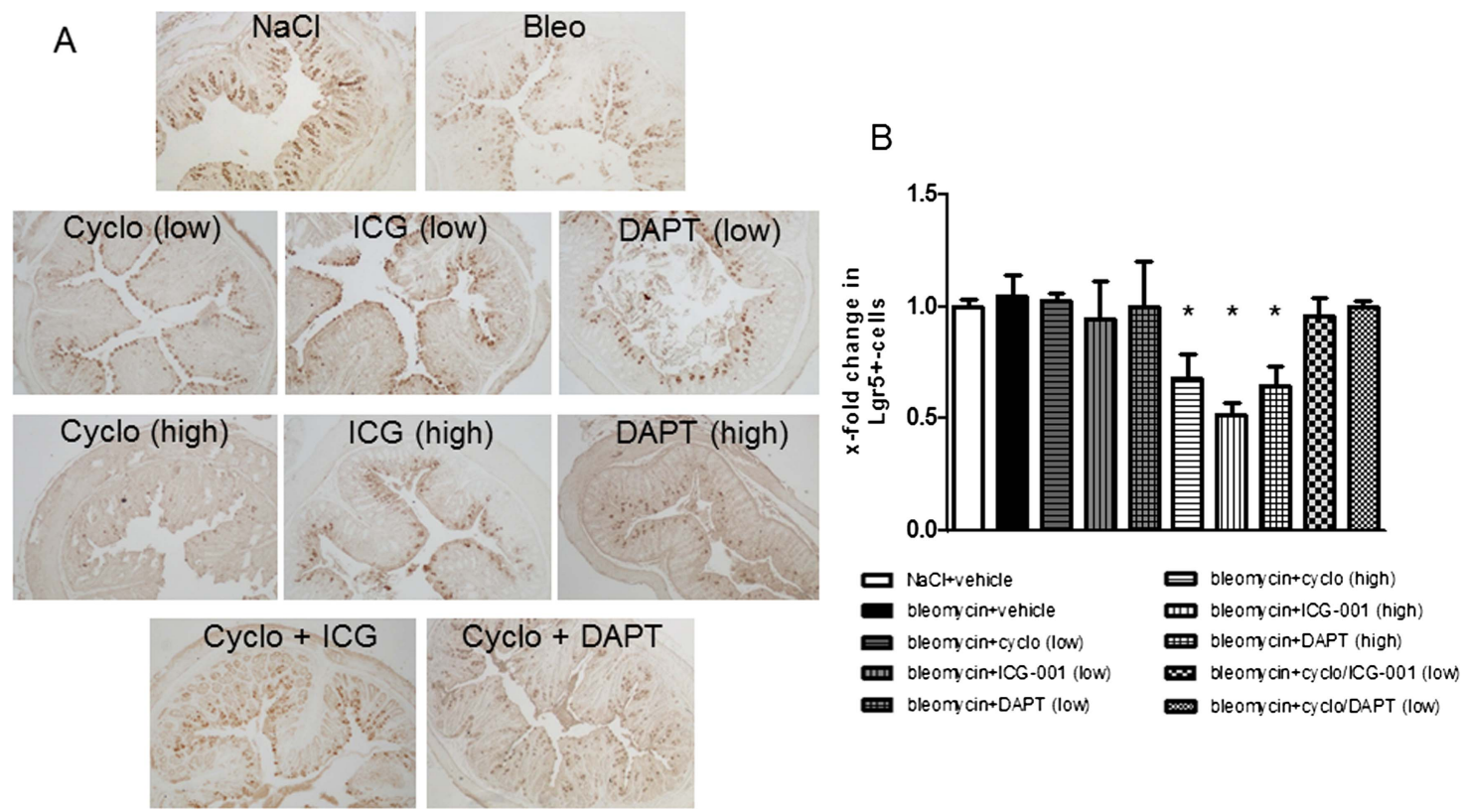

Figure 2 Combination therapies with morphogen pathway inhibitors are not limited by toxicity. (A) Representative images of Lgr5 stainings at 200-fold magnification. (B) Number of Lgr5+-intestinal stem cells. *indicates significant differences compared with vehicle-treated, bleomycin-challenged mice. 
A

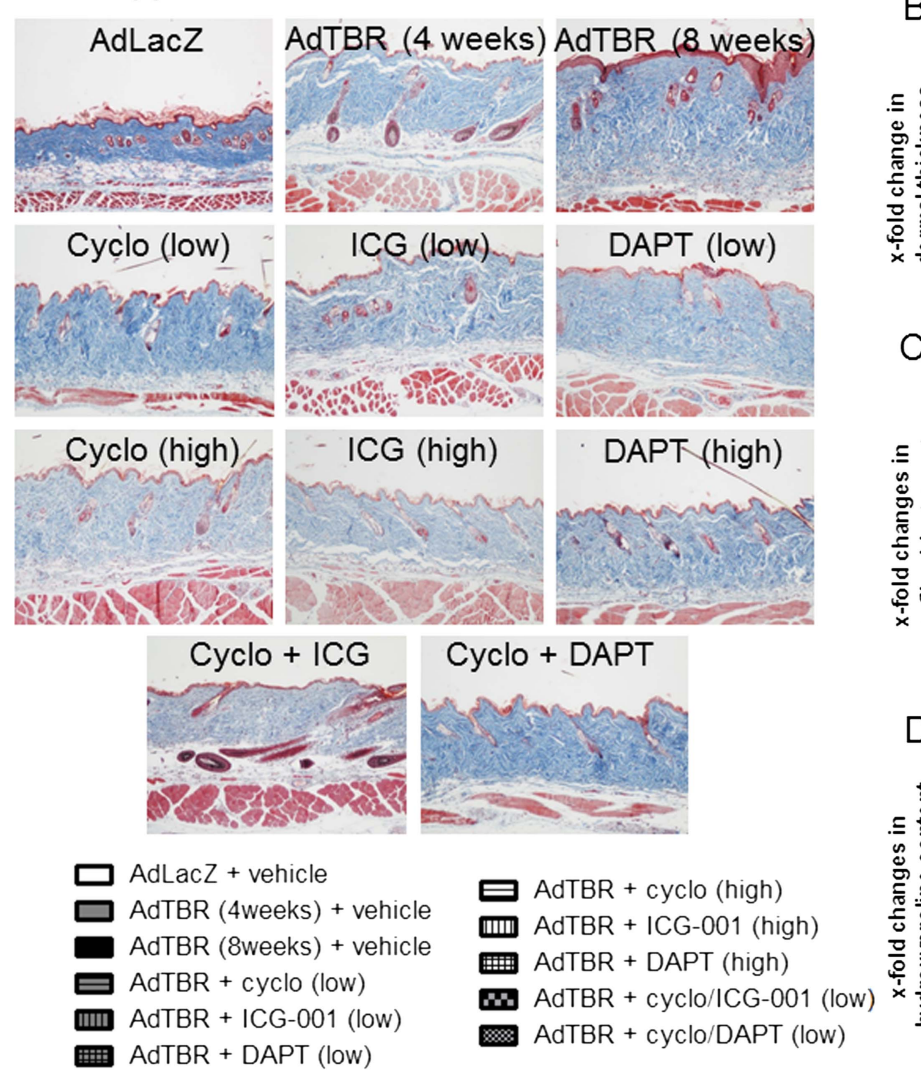

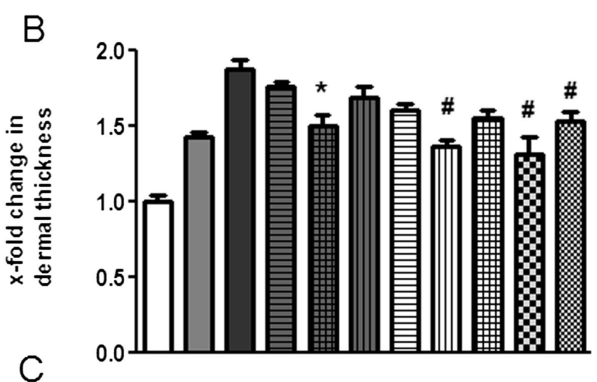

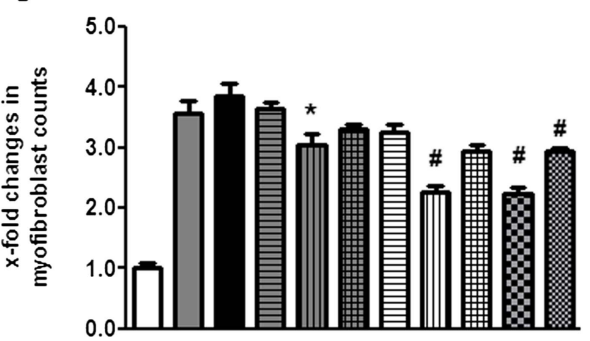

D

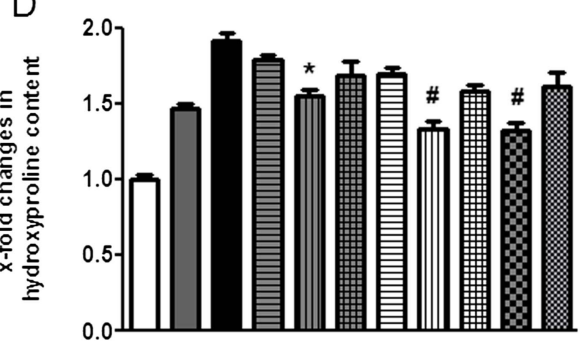

Figure 3 Combination therapies with morphogen pathway inhibitors are effective for the treatment of pre-established constitutively active TGF- $\beta$ receptor type I (AdTBR)-induced fibrosis. (A) Representative Trichrome stained skin section at 100-fold magnification. Effects of the different treatment regimens on skin thickening (B), myofibroblast differentiation (C) and accumulation of collagen (D). * indicates significant differences compared with vehicle-treated, AdTBR-challenged mice. \# indicates significant decreases compared with low-dose monotherapy.

Notch pathways is generally not well understood and may depend on the cellular context. Thus, further studies are required to characterise the interaction of different morphogen pathways in SSc.

Acknowledgements We thank Regina Kleinlein, Monica Pascuale Mate and Katja Dreißigacker for excellent technical assistance.

Contributors Design of the study: $A D$, TDV, VL, JHWD; Acquisition of data: $A D$, $\mathrm{VL}$, TDV, JH, YZ, CB, KP-Z; Interpretation of data: AD, VL, TDV, OD, GS, JHWD; Manuscript preparation: $A D, V L, O D, G S, J H W D$.

Funding Grants DI 1537/4-1, DI 1537/5-1, DI 1537/7-1, DI 1537/9-1, BE 5191/ 1-1, AK 144/1-1 and SCHE 1583/7-1 of the Deutsche Forschungsgesellschaft, grants A40 and J29 of the IZKF in Erlangen, the ELAN-Program of the University of

Erlangen-Nuremberg, the Wilhelm-Sander-Foundation and the Career Support Award of Medicine of the Ernst Jung Foundation.

Competing interests OD has consultancy relationships and/or has received research funding from Actelion, Pfizer, Ergonex, BMS, Sanofi-Aventis, United BioSource Corporation, Medac, Biovitrium, Boehringer Ingelheim, Novartis, 4D Science and Active Biotec in the area of potential treatments of scleroderma; JHWD has consultancy relationships and/or has received research funding from Actelion, Pfizer, Ergonex, BMS, Celgene, Bayer Pharma, Boehringer Ingelheim, JB Therapeutics, Sanofi-Aventis, Novartis, Array Biopharma and Active Biotec in the area of potential treatments of scleroderma and is stock owner of $4 D$ Science $\mathrm{GmbH}$.

Provenance and peer review Not commissioned; externally peer reviewed.

\section{REFERENCES}

1 Dale J, Alcorn N, Capell H, et al. Combination therapy for rheumatoid arthritis: methotrexate and sulfasalazine together or with other DMARDs. Nat Clin Pract Rheumatol 2007:3:450-8; quiz, following 478 .
2 Benza RL, Park MH, Keogh A, et al. Management of pulmonary arterial hypertension with a focus on combination therapies. J Heart Lung Transplant 2007;26:437-46

3 Akhmetshina A, Palumbo K, Dees C, et al. Activation of canonical Wnt signalling is required for TGF-beta-mediated fibrosis. Nat Commun 2012;3:735.

4 Bergmann C, Akhmetshina A, Dees C, et al. Inhibition of glycogen synthase kinase 3beta induces dermal fibrosis by activation of the canonical Wnt pathway. Ann Rheum Dis 2011;70:2191-8.

5 Beyer C, Schramm A, Akhmetshina A, et al. beta-catenin is a central mediator of pro-fibrotic Wnt signaling in systemic sclerosis. Ann Rheum Dis 2012;71:761-7.

6 Dees $C$, Tomcik M, Zerr $\mathrm{P}$, et al. Notch signalling regulates fibroblast activation and collagen release in systemic sclerosis. Ann Rheum Dis 2011;70:1304-10.

7 Dees C, Zerr P, Tomcik M, et al. Inhibition of Notch signaling prevents experimental fibrosis and induces regression of established fibrosis. Arthritis Rheum 2011;63:1396-404.

8 Distler A, Deloch L, Huang J, et al. Inactivation of tankyrases reduces experimental fibrosis by inhibiting canonical Wnt signalling. Ann Rheum Dis 2013;72:1575-80.

9 Horn A, Kireva T, Palumbo-Zerr K, et al. Inhibition of hedgehog signalling prevents experimental fibrosis and induces regression of established fibrosis. Ann Rheum Dis 2012;71:785-9.

10 Horn A, Palumbo K, Cordazzo C, et al. Hedgehog signaling controls fibroblast activation and tissue fibrosis in systemic sclerosis. Arthritis Rheum 2012;64:2724-33.

11 Kavian N, Servettaz A, Mongaret C, et al. Targeting ADAM-17/notch signaling abrogates the development of systemic sclerosis in a murine model. Arthritis Rheum 2010;62:3477-87.

12 Wei J, Fang F, Lam AP, et al. Wnt/beta-catenin signaling is hyperactivated in systemic sclerosis and induces Smad-dependent fibrotic responses in mesenchymal cells. Arthritis Rheum 2012:64:2734-45.

13 Wei J, Melichian D, Komura K, et al. Canonical Wnt signaling induces skin fibrosis and subcutaneous lipoatrophy: a novel mouse model for scleroderma? Arthritis Rheum 2011;63:1707-17.

14 Bayle J, Fitch J, Jacobsen K, et al. Increased expression of Wnt2 and SFRP4 in Tsk mouse skin: role of Wnt signaling in altered dermal fibrillin deposition and systemic sclerosis. J Invest Dermatol 2008;128:871-81. 


\section{Basic and translational research}

15 Zerr P, Palumbo-Zerr K, Distler A, et al. Inhibition of hedgehog signaling for the treatment of murine sclerodermatous chronic graft-versus-host disease. Blood 2012;120:2909-17.

16 Beyer $\mathrm{C}$, Reichert $\mathrm{H}$, Akan $\mathrm{H}$, et al. Blockade of canonical Wnt signaling ameliorates experimental dermal fibrosis. Ann Rheum Dis 2013;72:1255-8.

17 Yeung TM, Chia LA, Kosinski CM, et al. Regulation of self-renewal and differentiation by the intestinal stem cell niche. Cell Mol Life Sci 2011;68:2513-23.
18 Beyer C, Dees C, Distler JH. Morphogen pathways as molecular targets for the treatment of fibrosis in systemic sclerosis. Arch Dermatol Res 2013;305: $1-8$.

19 Dees C, Akhmetshina A, Zerr P, et al. Platelet-derived serotonin links vascular disease and tissue fibrosis. J Exp Med 2011;208:961-72.

20 Barker $\mathrm{N}$, van Es JH, Kuipers J, et al. Identification of stem cells in small intestine and colon by marker gene Lgr5. Nature 2007;449:1003-7. 


\section{ARD Combined inhibition of morphogen pathways demonstrates additive antifibrotic effects and improved tolerability}

Alfiya Distler, Veronika Lang, Tina Del Vecchio, Jingang Huang, Yun Zhang, Christian Beyer, Neng-Yu Lin, Katrin Palumbo-Zerr, Oliver Distler, Georg Schett and Jörg HW Distler

Ann Rheum Dis 2014 73: $1264-1268$ originally published online January 20, 2014

doi: 10.1136/annrheumdis-2013-204221

Updated information and services can be found at:

http://ard.bmj.com/content/73/6/1264

These include:

Supplementary Material

References

Email alerting service
Supplementary material can be found at:

http://ard.bmj.com/content/suppl/2014/01/21/annrheumdis-2013-2042 21.DC1.html

This article cites 20 articles, 8 of which you can access for free at: http://ard.bmj.com/content/73/6/1264\#BIBL

Receive free email alerts when new articles cite this article. Sign up in the box at the top right corner of the online article.

Topic

Articles on similar topics can be found in the following collections

Collections Connective tissue disease (4235)

\section{Notes}

To request permissions go to:

http://group.bmj.com/group/rights-licensing/permissions

To order reprints go to:

http://journals.bmj.com/cgi/reprintform

To subscribe to BMJ go to:

http://group.bmj.com/subscribe/ 